\title{
The Herd Behavior of Risk-Averse Investor Based on Information Cost
}

\author{
Guangming Deng \\ College of Science, Guilin University of Technology, Guilin, China \\ Email: dgm@glut.edu.cn
}

Received November $11^{\text {th }}$, 2013; revised December $11^{\text {th }}, 2013$; accepted December $18^{\text {th }}, 2013$

\begin{abstract}
Copyright (C) 2013 Guangming Deng. This is an open access article distributed under the Creative Commons Attribution License, which permits unrestricted use, distribution, and reproduction in any medium, provided the original work is properly cited.
\end{abstract}

\begin{abstract}
In this paper, the traditional model of herd behavior was improved and extended. The herd behavior of risk-averse investor based on information cost was studied in the financial market. By refining the concept of Bayes equilibrium and the analysis of the behavior of investors, it was discovered that the herd behavior of the second risk-averse investor did not produce until the first risk-averse investors chose to buy information.
\end{abstract}

Keywords: Risk Avoidance; Information Cost; Herd Behavior

\section{Introduction}

Herding behavior of financial markets refers that the majority of individual investors tend to take the same or similar investment strategy with the others when making investment decisions. Causes of herd behavior include information asymmetry, the concern for the reputation and rewards programs (Sharma \& Bikhchandani, 2000), where the information asymmetry caused by the spread of information is an important reason for herd behavior. Banerjee (1992) was first proposed based on asymmetric information model of herd behavior. Bikhchandani, Hirshleifer and Welch $(1992,1998)$ also studied the relevant herd behavior model, although both models are different, they all believe that information diffusion is the cause of herd behavior.

As BHW model assumes that investors can get free private information, Cui Wei (2008) for the real market, raised the cost of herd behavior based on the information model, However, BHW model also assumes that investors are risk neutral, in which most investors in financial markets do not match the characteristics of risk aversion. In this paper, BHW model was further extension studied, and we analyzed the risk-averse investor herd behavior based on information costs, and by refining the concept and inductive method of Bayesian risk aversion of investors so as to get the optimal decision-making behavior.

\section{The Model of Risk-Averse Investor Herd Behavior Based on the Information Cost}

In this paper, the traditional basis of BHW model, the introduction of investor risk aversion in financial markets and the presence of the characteristics of information costs, with a negative exponential utility function is the risk aversion of investors, the cost of herd behavior based on the information model. Basic model assumptions are as follows:

1) The investment result $v \in V=\{-1,1\}$ in the beginning is determined randomly. $v=1$ represents investment result is well and $v=-1$ represents investment result is bad. $v$ is equally likely to take on the values of 1 and -1 .

2) Each of the investors chooses whether to buy private signal before making a decision. Let $c_{i}$ denote the cost that investment $i$ purchase information, assuming $0 \leq c_{i} \leq 1$.

3) Let $s_{i} \in S=\{-1,1\}$ denote that private signal investor $i$ receives. $s=1$ denotes a good signal, $s=-1$ denotes a bad signal. Conditions in the investment result, the investor's private signal is independent.

4) $p_{i}$ stands for the accuracy of the investor $i$ acquires private signal, it is a function of the information cost $c_{i}$, denoted as $p_{i}=p\left(c_{i}\right)$ and $\frac{1}{2} \leq p_{i} \leq 1$. Accuracy refers to the probability of signal correct on the conditions given investment, and $p^{\prime}(c)>0, p(0)=\frac{1}{2}$. It is assumed that the information cost can be observed. The following investors can infer signal accuracy according to information cost the previous investors paid for.

5) $a_{i} \in A=\{0,1\}$ denotes the investment decisions of investors. $a=1$ stands for the decision to invest and $a=-1$ for decision not to invest.

6) The information set of investor $i$ is observed in front of all his investment decisions $h_{i}=\left(a_{1}, a_{2}, \cdots, a_{i-1}\right)$ of investors and their private information. Section $i$ of the public belief $\mu_{i}=P\left(v=1 \mid h_{i}\right)$, that investment in the historical conditions $h_{i}$, we get the probability of good investment results.

7) Investors using negative exponential utility function, the choice to buy private information, risk aversion returns to investors depends on information costs, investment decisions and investment results, defined as follows:

$$
u_{i}\left(a_{i}, c_{i}, v\right)=-\mathrm{e}^{-\alpha v a_{i}}-c_{i}
$$

In the case of uncertain future, investors expected return is conditional expectation of $u_{i}\left(a_{i}, c_{i}, v\right)$ under the condition of the information set. 


$$
\begin{aligned}
& E\left[u_{i}\left(a_{i}, c_{i}, v\right) \mid h_{i}, s_{i}\right] \\
& =P\left(s_{i}=1 \mid h_{i}\right) \times E\left[u_{i}\left(a_{i}, c_{i}, v\right) \mid h_{i}, s_{i}=1\right] \\
& +P\left(s_{i}=-1 \mid h_{i}\right) \times E\left[u_{i}\left(a_{i}, c_{i}, v\right) \mid h_{i}, s_{i}=-1\right]
\end{aligned}
$$

where

$$
\begin{gathered}
E u_{i}\left(a_{i}, c_{i}, v\right)= \begin{cases}-1-c_{i}, & a_{i}=0 \\
E\left[\left(-\mathrm{e}^{-\alpha v}\right) \mid h_{i}, s_{i}\right]-c_{i}, & a_{i}=1\end{cases} \\
E\left[\left(-\mathrm{e}^{-\alpha v}\right) \mid h_{i}, s_{i}\right] \\
=P\left(v=1 \mid h_{i}, s_{i}\right) \times\left(-\mathrm{e}^{-\alpha \times 1}\right)+P\left(v=-1 \mid h_{i}, s_{i}\right) \times\left(-\mathrm{e}^{\alpha \times(-1)}\right)
\end{gathered}
$$

Without purchasing information, the risk aversion of investors expected return is:

$$
\begin{aligned}
E\left[u_{i}^{N}\left(a_{i}, v\right) \mid h_{i}\right]= \begin{cases}-1, & a_{i}=0 \\
E\left[\left(-\mathrm{e}^{-\alpha v}\right) \mid h_{i}\right], & a_{i}=1\end{cases} \\
\begin{aligned}
E\left[\left(-\mathrm{e}^{-\alpha v}\right) \mid h_{i}\right] & =P\left(v=1 \mid h_{i}\right) \times\left(-\mathrm{e}^{-\alpha}\right)+P\left(v=-1 \mid h_{i}\right) \times\left(-\mathrm{e}^{\alpha}\right) \\
& =\mu_{i} \times\left(-\mathrm{e}^{-\alpha}\right)+\left(1-\mu_{i}\right) \times\left(-\mathrm{e}^{\alpha}\right) \\
& =\left(\mathrm{e}^{\alpha}-\mathrm{e}^{-\alpha}\right) \times \mu_{i}-\mathrm{e}^{\alpha}
\end{aligned}
\end{aligned}
$$

\section{Risk-Averse Investors Decision Analysis}

After comparing the purchase information and do not purchase information expected return, risk averse investors before deciding whether to buy information. This section uses the Bayesian algorithm and the inductive method to analyze investors optimal information cost and make the optimal investment decisions to maximize the expected return.

\section{The First Risk Averse Investor's Investment Decisions A1}

In order to analyze the first investor risk aversion A1 investment decisions, you first need to discuss the situation given information costs, and then further discuss the best information costs.

\section{Case Given Information Costs}

Information costs are assumed, the signal accuracy is. According to Bayes rule, in the purchase of information, the first investor risk aversion investment results A1 update their beliefs as:

$$
\begin{aligned}
& P\left(v=1 \mid h_{1}, s_{1}=1\right) \\
& \quad=\frac{P\left(h_{1}, s_{1}=1 \mid v=1\right) P(v=1)}{P\left(h_{1}, s_{1}=1 \mid v=1\right) P(v=1)+P\left(h_{1}, s_{1}=1 \mid v=-1\right) P(v=-1)} \\
& \quad=p\left(c_{1}\right) \\
& P\left(v=1 \mid h_{1}, s_{1}=-1\right)=1-p\left(c_{1}\right)
\end{aligned}
$$

If you get a good signal A1, then A1 investment results are good update belief; if A1 get is bad signal, then the result is good for investors A1 updated belief. A1 in getting a good signal and bad signal to make investment decisions after the ex- pected benefits are:

$$
\begin{aligned}
E & {\left[u_{1}\left(a_{1}=1, c_{1}, v\right) / h_{1}, s_{1}=1\right] } \\
= & E\left[\left(-\mathrm{e}^{-\alpha \times v}\right) / h_{1}, s_{1}=1\right]-c_{1} \\
= & P\left(v=1 \mid h_{1}, s_{1}=1\right) \times\left(-\mathrm{e}^{-\alpha \times 1}\right) \\
& +P\left(v=-1 \mid h_{1}, s_{1}=1\right) \times\left(-\mathrm{e}^{-\alpha \times(-1)}\right)-c_{1} \\
= & p\left(c_{1}\right) \times\left(-\mathrm{e}^{-\alpha \times 1}\right)+\left[1-p\left(c_{1}\right)\right] \times\left(-\mathrm{e}^{-\alpha \times(-1)}\right)-c_{1} \\
E & {\left[u_{1}\left(a_{1}=1, c_{1}, v\right) \mid h_{1}, s_{1}=-1\right] } \\
= & E\left[\left(-\mathrm{e}^{-\alpha \times v}\right) \mid h_{1}, s_{1}=-1\right]-c_{1} \\
= & P\left(v=1 \mid h_{1}, s_{1}=-1\right) \times\left(-\mathrm{e}^{-\alpha \times 1}\right) \\
& +P\left(v=-1 \mid h_{1}, s_{1}=-1\right) \times\left(-\mathrm{e}^{-\alpha \times(-1)}\right)-c_{1} \\
= & {\left[1-p\left(c_{1}\right)\right] \times\left(-\mathrm{e}^{-\alpha \times 1}\right)+p\left(c_{1}\right) \times\left(-\mathrm{e}^{-\alpha \times(-1)}\right)-c_{1} }
\end{aligned}
$$

There

$$
E\left[u_{1}\left(a_{1}, c_{1}, v\right) \mid h_{1}, s_{1}=-1\right]<E\left[u_{1}\left(a_{1}=0, c_{1}, v\right) \mid h_{1}, s_{1}\right]=-1-c_{1}
$$

So ended the first A1 in investor risk aversion will not be a bad signal for investment.

Proposition 1 Assume

$$
\frac{1}{2} \leq p\left(c_{1}\right) \leq 1,
$$

then

$$
E\left[u_{1}\left(a_{1}, c_{1}, v\right) \mid h_{1}, s_{1}=1\right]>-1-c_{1} .
$$

Proposition 1 is true can guarantee a good signal was observed after the first risk averse investor must invest A1. Otherwise, regardless of the resulting signal A1 is good or bad, A1 will not invest, so that investors behind the A1 will not be able to grasp the behavior of their access to real information. The second risk averse investors A2 and A1 will face the same situation, so A2 would not choose to invest, and after that all investors will not invest. Thus, if Proposition 1 is false, no one making investment decisions, and no one involved in the decision-making model.

Proposition 1 is equivalent to

$$
p\left(c_{1}\right)>\frac{1-\mathrm{e}^{\alpha}}{\mathrm{e}^{-\alpha}-\mathrm{e}^{\alpha}}
$$

Intuitively, since investors are risk averse, the accuracy of the signal must be larger to ensure investors.

In the case of Proposition 1 is true, A1 will make investment decisions according to its private signal, that is, while getting good signal $\left(s_{1}=1\right)$, A1 decided to invest in $\left(a_{1}=1\right)$; For the bad signal $\left(s_{1}=-1\right)$, A1 decided not to invest $\left(a_{1}=0\right)$. A1 in getting a good signal and bad signal the expected benefits respectively is:

$$
\begin{aligned}
& E\left[u_{1}\left(a_{1}, c_{1}, v\right) \mid h_{1}, s_{1}=1\right] \\
& =p\left(c_{1}\right) \times\left(-\mathrm{e}^{-\alpha \times 1}\right)+\left[1-p\left(c_{1}\right)\right] \times\left(-\mathrm{e}^{-\alpha \times(-1)}\right)-c_{1} \\
& =p\left(c_{1}\right) \times\left(\mathrm{e}^{\alpha}-\mathrm{e}^{-\alpha}\right)-\mathrm{e}^{\alpha}-c_{1} \\
& E\left[u_{1}\left(a_{1}, c_{1}, v\right) \mid h_{1}, s_{1}=-1\right]=-1-c_{1}
\end{aligned}
$$


The first risk aversion investor, the probability of obtaining good signals and bad A1 were 50\%, therefore, A1 expected return after purchase information is:

$$
\begin{aligned}
E & {\left[u_{1}\left(a_{1}, c_{1}, v\right) \mid h_{1}, s_{1}\right] } \\
= & P\left(s_{1}=1 \mid h_{1}\right) \times E\left[u_{1}\left(a_{1}, c_{1}, v\right) \mid h_{1}, s_{1}=1\right] \\
& +P\left(s_{1}=-1 \mid h_{1}\right) \times E\left[u_{1}\left(a_{1}, c_{1}, v\right) \mid h_{1}, s_{1}=-1\right] \\
= & \frac{1}{2} \times\left[p\left(c_{1}\right) \times\left(\mathrm{e}^{\alpha}-\mathrm{e}^{-\alpha}\right)-\mathrm{e}^{\alpha}-c_{1}\right]+\frac{1}{2}\left[-1-c_{1}\right] \\
= & \frac{\left(\mathrm{e}^{\alpha}-\mathrm{e}^{-\alpha}\right)}{2} \times p\left(c_{1}\right)-c_{1}-\frac{\mathrm{e}^{\alpha}+1}{2}
\end{aligned}
$$

If $\mathrm{A} 1$ chooses not to purchase information, the A1 for investment results for the good faith is the public belief, i.e. $\mu_{1}=\frac{1}{2}$, the A1 earnings should be:

$$
\begin{aligned}
& E\left[u_{1}^{N}\left(a_{1}, v\right) \mid h_{1}\right]=\frac{1}{2} \times\left[\frac{\left(\mathrm{e}^{\alpha}-\mathrm{e}^{-\alpha}\right)}{2}-\mathrm{e}^{\alpha}\right]+\frac{1}{2} \times(-1) \\
& =-\frac{\mathrm{e}^{\alpha}+\mathrm{e}^{-\alpha}+2}{4}
\end{aligned}
$$

Thus, when $E\left[u_{1}\left(a_{1}, c_{1}, v\right) \mid h_{1}, s_{1}\right]>E\left[u_{1}^{N}\left(a_{1}, v\right) \mid h_{1}\right]$ Namely,

$$
\begin{aligned}
& \frac{\left(\mathrm{e}^{\alpha}-\mathrm{e}^{-\alpha}\right)}{2} \times p\left(c_{1}\right)-c_{1}-\frac{\mathrm{e}^{\alpha}+1}{2}>-\frac{\mathrm{e}^{\alpha}+\mathrm{e}^{-\alpha}+2}{4} \\
& \Leftrightarrow\left(\mathrm{e}^{\alpha}-\mathrm{e}^{-\alpha}\right) \times p\left(c_{1}\right)-2 c_{1}-\frac{\mathrm{e}^{\alpha}-\mathrm{e}^{-\alpha}}{2}>0 \\
& \Leftrightarrow p\left(c_{1}\right)-\frac{2 c_{1}}{\mathrm{e}^{\alpha}-\mathrm{e}^{-\alpha}}-\frac{1}{2}>0
\end{aligned} .
$$

The first risk averse investors A1 is willing to buy private information.

Lemma 1

Assum $p^{\prime}(c)>0$,

$$
p\left(\frac{\mathrm{e}^{\alpha}-\mathrm{e}^{-\alpha}}{4}\right) \leq 1 \quad\left(\forall c \in\left[0, \frac{\mathrm{e}^{\alpha}-\mathrm{e}^{-\alpha}}{4}\right]\right),
$$

if and only if

$$
\exists c: p(c)-\frac{2 c}{\mathrm{e}^{\alpha}-\mathrm{e}^{-\alpha}}-\frac{1}{2}>0,
$$

the first risk aversion investor A1 purchases information.

\section{Proposition 2}

Assume $\exists c$, s. t.

$$
p(c)-\frac{2 c}{\mathrm{e}^{\alpha}-\mathrm{e}^{-\alpha}}-\frac{1}{2}>0,
$$

and

$$
\exists c \in\left[0, \frac{\mathrm{e}^{\alpha}-\mathrm{e}^{-\alpha}}{4}\right], p\left(\frac{\mathrm{e}^{\alpha}-\mathrm{e}^{-\alpha}}{4}\right) \leq 1 .
$$

Under the conditions in Lemma 1, Proposition 2 is true guarantee of a risk averse investor A1 never buys a private message. If A1 is not purchasing information, then the result is good for investment belief is 0.5 , the probability of investment is 0.5. So, A1 investment decisions investors will not give back any of the information transmitted, the second investor risk aversion and A1 A2 facing the same situation, empathy, A2, and behind all investors will not buy information, which model loses significance

\section{Optimal Cost of Information}

While purchasing information, A1 faced with the expected return on the following maximization problem:

$$
\begin{aligned}
& \max _{c_{1}}: p\left(c_{1}\right)-\frac{2 c_{1}}{\mathrm{e}^{\alpha}-\mathrm{e}^{-\alpha}}-\frac{1}{2} \\
& \text { s.t.: } p\left(c_{1}\right)-\frac{2 c_{1}}{\mathrm{e}^{\alpha}-\mathrm{e}^{-\alpha}}-\frac{1}{2}>0, p\left(c_{1}\right) \leq 1, c_{1} \geq 0
\end{aligned}
$$

A1 Optimal information cost $c_{1}^{*}$ meet

$$
p^{\prime}\left(c_{1}^{*}\right)=\frac{2}{\mathrm{e}^{\alpha}-\mathrm{e}^{-\alpha}},
$$

or $p\left(c_{1}^{*}\right)=1$ and

$$
0<c_{1}^{*} \leq \frac{\mathrm{e}^{\alpha}-\mathrm{e}^{-\alpha}}{4} .
$$

At the same time, the optimal investment decision A1 is make decisions according to their private signals, namely when the it gains signal $\left(s_{1}^{*}=1\right)$, A1 decided to invest $\left(a_{1}^{*}=1\right)$; when it gets bad signal, A1 decided not to invest.

\section{The Second Investor Risk Aversion A2 Investment Decisions}

The second risk averse investors A2 according to the optimal information cost $c_{1}^{*}$ of $\mathrm{A} 1$, can be speculated that $\mathrm{A} 1$ signal accuracy.

First, assume that $\mathrm{A} 1$ decided to invest $\left(a_{1}^{*}=1\right)$, this means that the A1 has good signal $\left(s_{1}^{*}=1\right)$. So A2 in the purchase information, update beliefs about investment results, also is the second period public faith $\mu_{2}$ :

$$
\begin{aligned}
& \mu_{2}=P\left(v=1 \mid h_{2}\right)=P\left(v=1 \mid a_{1}^{*}=1\right)=p\left(c_{1}^{*}\right) \\
& p\left(c_{1}^{*}\right)>\frac{1-\mathrm{e}^{\alpha}}{\mathrm{e}^{-\alpha}-\mathrm{e}^{\alpha}}
\end{aligned}
$$

So, in the absence of purchase information, the second risk avoidance investors A2 the optimal decision is a choice, and A2 after investment earnings are expected to be:

$$
E\left[u_{2}^{N}\left(a_{2}=1, v\right) \mid h_{2}\right]=\left(\mathrm{e}^{\alpha}-\mathrm{e}^{-\alpha}\right) \times p\left(c_{1}^{*}\right)-\mathrm{e}^{\alpha}>-1
$$

Then, the second risk aversion investor A2 in buying information and not to buy the expected return of the comparison. If the given information for cost, when the A2 is a good sign, she updated belief as the result of the investment:

$$
\begin{aligned}
& P\left(v=1 \mid h_{2}, s_{2}=1\right) \\
& =\frac{P\left(h_{2}, s_{2}=1 \mid v=1\right) P(v=1)}{P\left(h_{2}, s_{2}=1 \mid v=1\right) P(v=1)+P\left(h_{2}, s_{2}=1 \mid v=-1\right) P(v=-1)} \\
& =\frac{p\left(c_{1}^{*}\right) p\left(c_{2}\right)}{p\left(c_{2}\right) p\left(c_{1}^{*}\right)+\left[1-p\left(c_{2}\right)\right]\left[1-p\left(c_{1}^{*}\right)\right]} \\
& =\frac{p\left(c_{1}^{*}\right) p\left(c_{2}\right)}{1-p\left(c_{1}^{*}\right)-p\left(c_{2}\right)+2 p\left(c_{2}\right) p\left(c_{1}^{*}\right)}>\frac{1}{2} .
\end{aligned}
$$


A2, therefore, decided to invest in.

When the A2 is bad signal, she updated belief as the result of the investment:

$$
\begin{aligned}
P\left(v=1 \mid h_{2}, s_{2}=-1\right) & =\frac{P\left(h_{2}, s_{2}=-1 \mid v=1\right) P(v=1)}{P\left(h_{2}, s_{2}=-1 \mid v=1\right) P(v=1)+P\left(h_{2}, s_{2}=-1 \mid v=-1\right) P(v=-1)} \\
& =\frac{p\left(c_{1}^{*}\right)\left[1-p\left(c_{2}\right)\right]}{\left[1-p\left(c_{2}\right)\right] p\left(c_{1}^{*}\right)+p\left(c_{2}\right)\left[1-p\left(c_{1}^{*}\right)\right]}=\frac{p\left(c_{1}^{*}\right)\left[1-p\left(c_{2}\right)\right]}{p\left(c_{1}^{*}\right)+p\left(c_{2}\right)-2 p\left(c_{1}^{*}\right) p\left(c_{2}\right)} .
\end{aligned}
$$

When $p\left(c_{1}^{*}\right)>p\left(c_{2}\right)$, the value is more than $\frac{1}{2}$, A2 decided to invest in; Otherwise, not investment.

The second risk aversion investor A2, the probability of obtaining good signals and bad, respectively is:

$$
\begin{aligned}
& P\left(s_{2}=1 \mid h_{2}\right)=1-p\left(c_{1}^{*}\right)-p\left(c_{2}\right)+2 p\left(c_{2}\right) p\left(c_{1}^{*}\right) \\
& P\left(s_{2}=-1 \mid h_{2}\right)=p\left(c_{1}^{*}\right)+p\left(c_{2}\right)-2 p\left(c_{1}^{*}\right) p\left(c_{2}\right)
\end{aligned}
$$

After the purchase information, A2 expected return is:

$$
E\left[u_{2}\left(a_{2}, c_{2}, v\right) \mid h_{2}, s_{2}\right]=P\left(s_{2}=1 \mid h_{2}\right) \times E\left[u_{2}\left(a_{2}, c_{2}, v\right) \mid h_{2}, s_{2}=1\right]+P\left(s_{2}=-1 \mid h_{2}\right) \times E\left[u_{2}\left(a_{2}, c_{2}, v\right) \mid h_{2}, s_{2}=-1\right]
$$

where

$$
\begin{gathered}
E\left[u_{2}\left(a_{2}, c_{2}, v\right) \mid h_{2}, s_{2}=1\right]=E\left[\left(-\mathrm{e}^{-\alpha \times v}\right) \mid h_{2}, s_{2}=1\right]-c_{2}=P\left(v=1 \mid h_{2}, s_{2}=1\right) \times\left(-\mathrm{e}^{-\alpha \times 1}\right)+P\left(v=-1 \mid h_{2}, s_{2}=1\right) \times\left(-\mathrm{e}^{-\alpha \times(-1)}\right)-c_{2} \\
=\frac{p\left(c_{1}^{*}\right) p\left(c_{2}\right)}{P\left(s_{2}=1 \mid h_{2}\right)} \times\left(-\mathrm{e}^{-\alpha \times 1}\right)+\left[1-\frac{p\left(c_{1}^{*}\right) p\left(c_{2}\right)}{P\left(s_{2}=1 \mid h_{2}\right)}\right] \times\left(-\mathrm{e}^{-\alpha \times(-1)}\right)-c_{2} \\
E\left[u_{2}\left(a_{2}, c_{2}, v\right) \mid h_{2}, s_{2}=-1\right]=-1-c_{2}
\end{gathered}
$$

When $p\left(c_{1}^{*}\right)>p\left(c_{2}\right)$, that is, the second risk aversion investor A2 signal is not the first risk aversion investor A1 signal accurately

$$
E\left[u_{2}\left(a_{2}, c_{2}, v\right) \mid h_{2}, s_{2}\right]=\left(\mathrm{e}^{\alpha}-\mathrm{e}^{-\alpha}\right) \times p\left(c_{1}^{*}\right)-\mathrm{e}^{\alpha}-c_{2} .
$$

A2 buys private information after the expected return $\left(\mathrm{e}^{\alpha}-\mathrm{e}^{-\alpha}\right) \times p\left(c_{1}^{*}\right)-\mathrm{e}^{\alpha}-c_{2}$, less than expected earnings of not to buy private information

$$
E\left[u_{2}^{N}\left(a_{2}, v\right) \mid h_{2}\right]=\left(\mathrm{e}^{\alpha}-\mathrm{e}^{-\alpha}\right) \times p\left(c_{1}^{*}\right)-\mathrm{e}^{\alpha} .
$$

A2 will not buy private information, therefore, A2 will fully believe that the signal A1 and follow A1 investment decisions.

When $p\left(c_{1}^{*}\right) \leq p\left(c_{2}\right)$,

$$
\begin{aligned}
E\left[u_{2}\left(a_{2}, c_{2}, v\right) \mid h_{2}, s_{2}\right] & =P\left(s_{2}=1 \mid h_{2}\right) \times\left\{\frac{p\left(c_{1}^{*}\right) p\left(c_{2}\right)}{P\left(s_{2}=1 \mid h_{2}\right)} \times\left(-\mathrm{e}^{-\alpha \times 1}\right)+\left[1-\frac{p\left(c_{1}^{*}\right) p\left(c_{2}\right)}{P\left(s_{2}=1 \mid h_{2}\right)}\right] \times\left(-\mathrm{e}^{-\alpha \times(-1)}\right)-c_{2}\right\}+P\left(s_{2}=-1 \mid h_{2}\right) \times\left(-1-c_{2}\right) \\
& =\left(2-e^{\alpha}-e^{-\alpha}\right) \times p\left(c_{1}^{*}\right) p\left(c_{2}\right)+\left(\mathrm{e}^{\alpha}-1\right) \times p\left(c_{1}^{*}\right)+\left(\mathrm{e}^{\alpha}-1\right) \times p\left(c_{2}\right)-c_{2}-\mathrm{e}^{\alpha}
\end{aligned}
$$

Only when $E\left[u_{2}\left(a_{2}, c_{2}, v\right) \mid h_{2}, s_{2}\right]>E\left[u_{2}^{N}\left(a_{2}, v\right) \mid h_{2}\right]$, that is

$$
\left(2-\mathrm{e}^{\alpha}-\mathrm{e}^{-\alpha}\right) \times p\left(c_{1}^{*}\right) p\left(c_{2}\right)+\left(\mathrm{e}^{-\alpha}-1\right) \times p\left(c_{1}^{*}\right)+\left(\mathrm{e}^{\alpha}-1\right) \times p\left(c_{2}\right)-c_{2}>0 \Rightarrow\left(2-\mathrm{e}^{\alpha}-\mathrm{e}^{-\alpha}\right)+\left(\mathrm{e}^{-\alpha}-1\right)+\left(\mathrm{e}^{\alpha}-1\right)-c_{2}>0 \Rightarrow c_{2}<0,
$$

The second risk avoidance investors A2 will buy private information, and according to its private signal making investment decisions. Obviously, A2 buy private information conditions cannot be met.

So when $p\left(c_{1}^{*}\right) \leq p\left(c_{2}\right)$, A2 will not purchase information. Synthetically the above two kinds of circumstances, if the first risk aversion investor A1 bought the most accurate information and investment, then the second risk aversion investor A2 will follow A1 investment decisions.

Next, the discussion on the first risk-averse investors A1 do not invest. If the A1 is not investment $\left(a_{1}^{*}=0\right)$, so that she will get the bad signal $\left(s_{1}^{*}=-1\right)$. A similar analysis can get the condition of second risk averse investors A2 buy private information is:

$$
\left(2-\mathrm{e}^{\alpha}-\mathrm{e}^{-\alpha}\right) \times p\left(c_{1}^{*}\right) p\left(c_{2}\right)+\left(\mathrm{e}^{-\alpha}-1\right) \times p\left(c_{1}^{*}\right)+\left(\mathrm{e}^{\alpha}-1\right) \times p\left(c_{2}\right)-c_{2}>0
$$

Also shows that A2 can be not buy private information, A2 will follow A1's decision and choose not to invest, the expected return to A2.

$$
E\left[u_{2}{ }^{N}\left(a_{2}=0, v\right) \mid h_{2}\right]=-1
$$


Therefore, whether the first risk averse investors whether A1 investment, second risk averse investors A2 will not purchase information, private information A2 can take full advantage of A1 buy, and follow A1's investment decision.

\section{Investment Decision No.N Risk Averse Investors in AN}

We can use similar methods to analysis behind all the risk averse investors. Investment behavior if the second risk averse investors A2 not buy private information and imitate A1, A2 behavior cannot risk on the back of the investors to avoid any information reveals the role of. Then, the third risk averse investors A3 is facing the same situation and A2, A3 and A2 will make the same decision, which mimics the first risk averse investors A1 investment behavior without the purchase of private information. Next, A4, A5... AN will make the same decision. So, all investors are behind the first risk averse investors follow A1 behavior, and will not buy private information. Therefore, information diffusion and herding from second risk averse investors A2 began.

\section{Conclusion}

This paper, based on the BHW model, considering the characteristics of investors in financial markets, risk aversion, and the introduction of information cost, discusses the risk investors herd behavior based on information cost. Through the research of risk averse investors found, only the first risk averse investors are willing to buy information, the optimal information cost is $c_{1}^{*}$, and meet:

$$
p^{\prime}\left(c_{1}^{*}\right)=\frac{2}{\mathrm{e}^{\alpha}-\mathrm{e}^{-\alpha}}
$$

or $p\left(c_{1}^{*}\right)=1$ and

$$
0<c_{1}^{*} \leq \frac{\mathrm{e}^{\alpha}-\mathrm{e}^{-\alpha}}{4}
$$

Starting from the second risk aversion investor, all the risk aversion of investors behind will not purchase information, and follow the first risk aversion of investors behavior. In addition, the information cost and risk aversion of investors decisionmaking model, information diffusion and herd behavior will occur, and from the second risk avoidance investors are starting to happen.

\section{Acknowledgements}

This work was jointly supported by the National Social Science Fund (No.13BTJ009), and the Guangxi Key Laboratory of Spatial Information and Geomatics (No.1207115-27).

\section{REFERENCES}

Sharma, S., \& Bikhchandani, S. (2000). Herd behavior in financial markets: A review [J]. IMF Working Paper.

Banerjee, A. V. (1992) A simple model of herd behavior [J]. The Quarterly Journal of Economics. 107, 797-817. http://dx.doi.org/10.2307/2118364

Bikhchandani, S., Hirshleifer, D., \& Welch, I. (1992). A theory of fads, fashion, custom, and cultural change as informational cascades [J]. The Journal of Political Economy, 100, 992-1026. http://dx.doi.org/10.1086/261849

Bikhchandani, S. Hirshleifer, D., \& Welch, I. (1998). Learning from the behavior of others: Conformity, fads, and the informational cascades [J]. Journal of Economics Perspectives, 12, 151-170. http://dx.doi.org/10.1257/jep.12.3.151

Cui, W. (2008). Information costs and herd behavior in financial markets-For the improvement and expansion of BHW model [J]. Economic Science, 6, 91-99. 